\title{
Commentary
}

\section{General Theory and Local Action: Experiences from the Quality of Working Life Movement'}

\section{Bjørm Gustavsen}

Professor emeritus, Work Research Institute Oslo/National Institute for Working Life, Stockholm ${ }^{2}$

\begin{abstract}
Quality of Working Life was a researcher-driven social movement culminating in the early 1980s. Its 1981 conference had some 2000 participants from research, management, unions, and government from about 30 countries. Their unifying idea was that the kind of workplace organization demonstrated in the Industrial Democracy Experiments had an emancipatory potential for democracy, productivity, and health in the workplace and beyond. A key question remained, however: how could this transformation take place on a large scale in society? There were different attempts within the movement at combining the general frameworks required to maintain societal significance and impact on the one hand, at the same time as creating relevant knowledge for the local context. After leaving the initial ambition of a universal theory, a turn toward purely local development work was again followed by a return to the general, not as the foundation of a general theory but as elements in a social movement.
\end{abstract}

\section{KEYWORDS}

Quality of Working Life Movement / Industrial Democracy / theories of organization / theory of science

\section{Introduction}

hen the Industrial Demcracy (ID) program in Norway helped raise a global interest in autonomy in work, an effort was made to create a platform for making actors move from interest to action and for forming a global movement where different initatives could support each other. It is not possible to give an exact description of how far the movement reached and what activities to which it gave rise, but projects seem to have appeared in as much as 30 countries ranging from the US to India and from Norway to Italy (Quality of Working Life Council, 1977; Ejnatten, 1993). Called 'Quality of Working Life', the movement had an elected council that organized joint activites like conferences and publications.

Although a number of people contributed to the theoretical platform, its main architect was Fred Emery. For a while, it also seemed successful: a movement with branches in a number of countries emerged and seemed to gain an increasing momentum throughout the 1970s and into the 80s (an overview up to about 1990 can be found in Ejnatten, 1993). A conference in 1981 attracted about 2000 participants. Perhaps more important

\footnotetext{
${ }^{1}$ You can find this text and its DOI at https://tidsskrift.dk/njwls/index.

${ }^{2}$ Corresponding email address: bjoerngustavsen@gmail.com.
} 
than the number of participants was what kind of participants: not only researchers but also managers and union representatives from several countries representing major industries like the automobile industry as well as major employer and union confederations. The door seemed to be open for a major global impact. The conference became, however, the only event of its kind and by the end of the 1980s most of the collaboration intended by the Quality of Working Life (QWL) movement had withered away. This did not mean that the perspectives on work made manifest through the ID program were obsolete. Relevant projects continued in many parts of the world, but the univeral reasons behind them had evaporated. What took place in terms of continued developments had a strong local and contextual character.

Below, an outline of the ideas behind the QWL movement will be given, together with an effort at identifying the reasons for its decline as a steering mechanism for practical efforts, concluding with a discussion of the reconstruction of QWL theory.

\section{Turbulence and democracy}

With work and its emanciption as the core theme, Emery shared his point of departure with Marx. However, closely related to Marxist thought Emery may have been in his early phase, he also clearly jumped off around the time of the Soviet invasion in Hungary in 1956. Like a number of Western intellectuals, Emery set out to create a theory that could maintain the strong aspects of Marxist thinking while it could renew those aspects where Marxism had gone wrong. The call was for a theory that could more adequately reflect the demands and potentials of work and how to turn it into a free and creative activity for everybody under realistic socio-economic conditions.

On this background, Emery moved to the Tavistock Institute in London where Eric Trist and colleagues had already opened up a pathbreaking work research tradition centering on the notion of autonomy in work. In their first reports, Trist and colleagues expressed themselves in a case-oriented, participant observer style (i.e., Trist \& Bamforth, 1951). Since a few cases could hardly constitute the platform for a theory able to compete, be it with Marxism or any other grand theory. Emery's first move was to translate the case material into a systems theoretical framework. Through seeing case events in the light of concepts like open systems, steady state, redundancy, equifinality, directive correlations, and similar, Emery intended to lift the cases to a status of general validity (Emery, 1959; for a further presentation of his concepts and their sources see Emery, 1969). Emery must, however, not be seen simply as one of the many adherents of the notion of a general systems theory (GST) appearing at the time. It is when we turn to the way he used this kind of theory and the contributions that he made that his role as a constructor of theory can be more correctly assessed.

The core concept in his version of GST was the notion of open systems. All organizations face an environment and the productive, adaptive, and innovative mechanisms at work in the organization refer to the transactions between the organization and its environment. On this background, Emery made a typology of organizational environments, distingushing between the placid, random environment, the clustered environment, the disturbed-reactive environment, and the environment with a potential for turbulence. The more specific characteristics of these environments are spelled out in the study by Emery and Trist (1965). The main dimension underlying these catergories is the degree

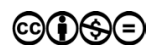


of organization in the environment. At the one end, the random environment - closely resembling the market of free competion - contains no links between organizations, while, at the other end, links, ties, and channels where impulses can move, constitute an exceedingly complex system. No single actor or group of actors can overlook the whole situation and even small disturbances appearing at one point can be magnified into unpredictable diffusion and major upheavals.

While most organizations at most times confront fairly stable environments, all organizations will, now and then, face turbulence. Since turbulence can have major consequences - such as wiping out large numbers of organizations - all organizations need to be able to handle the challenges associated with turbulence. While people at work confront numerous challenges, large and small, those associated with turbulence constitue the challenge superior to all other challenges and, consequently, the one for which any notion of work and organization has to prepare.

Since processes of turbulence cannot be overlooked and rationally understood, no amount of rational planning, strategic thinking, and similar can handle the situation. Turbulence can be handled only through the emergence of values that are shared between the actors concerned. Nobody will, however, commit themselves to values in the creation of which they have not taken part. To take part in value-generating processes, the individual must be free. Links, ties, and bonds between people where some rely on power are not values but commands. They can promote obedience but not committment.

What is called for is a set of relationships between actors based on each actor recognizing the other actors as being equal to him- or herself (Emery was no adherent of German philosophy but could have called upon Hegel on this point). In building these relationships bottom-up, there is a need to start with the near environment; for most people the workplace. In developing his views on the value-driven organization, Emery used several sources, in particular Selznick (1957) and such notions as distinctive competence, mutual trust, and pride in the organization. Participation in the generation of values that are to drive an organization provides a platform for participation in values pertaining to the boader society, such as relationships based on trust and commitment to democratic forms of communication. This line of reasoning appears in a sketchy form and gives rise to many questions. The core point in this context is, however, not all the unanswered questions but that the reasoning constituted the ultimate theoretical foundation for promoting autonomy in work. Most of the people who joined the QWL movement did it from a wish to promote democracy. Issues like productivity and innovation were important as well, but for Emery, peak performance in such areas was dependent upon a broader democratic framework.

To make these ideas become social realities to an extent sufficient to handle reallife cases of turbulence was a major challenge. Just because it was major, the quality of working life movement was formed to promote the ideas and trigger projects in as many countries as possible in the hope that a self-sustaining process of reconstruction could be created. When Emery took a leadership position in the movement, it was on the background of the close link between theory and action found in his thinking. He developed a number of instruments to be applied in practical work, for instance the search conference (Emery \& Emery, 1978). In a search conference, the participants set out to jointly discover the characertistics of their environment. To Emery, it is of major importance that all participants are given the same space and the same possibilites for participating 
in the process. Practical knowledge is seen as being of a value fully equal to theoretical knowledge. In fact, Emery saw much academic knowledge as efforts to perform the impossible: to theoretically point out how to counter turbulence.

Emery's theoretical construction can be made subject to academic critique on a number of points, for instance that it is little more than a sketch concerning the conditions and measures needed to really influence working life in major parts of the world. To this kind of critique, Emery could, however, answer that the validity of the theory was not to be settled through academic discourse, but primarily through its ability to actually create a broad movement on the level of practices. The role of a theory is not to answer all questions but to drive a social movement. What we need to do, then, is not to go directly to academic counterarguments but to look at what practical problems appeared in the implementation of the ideas of the movement.

\section{A plurality of experiences}

In a publication from 1977 (Engelstad \& Ødegaard, 1977), the authors report from a job design seminar. This was one of the direct efforts at follow-up after the field experiments in Norway, organized with six enterprises participating each time. The program was intended to start with presentations of the challenges of working life, and a presentation of the ID projects as a response to these challenges, to be followed by a discourse aimed at identifying how to implement the responses - mainly the creation of autonomous work groups - in the participating organizations. The participating organizations represented by bipartite project goups - refused, however, to follow this pattern. Instead, they wanted to start by each presenting itself to the other participants and continue with discussing to what extent they could provide each other with relevant ideas concerning how to proceed in their own efforts. Only then were the enterprises interested in turning to examples «not present» to see if they could enrich a discussion that was already ongoing. While one could, on a high level of abstraction, say that the projects that came out of these discourses all had to do with autonomy and democracy, in practical terms, they showed a broad variation: there emerged projects not only on socio-technical redesign but also on training of supervisors, mapping of health and safety problems, the handling of absenteeism, and much more. From the international overview contained in The Quality of Working Life Council (1977), it can be seen that this kind of differentiation did not pertain to the Norwegian development only. Whatever could be assumed in terms of underlying general aspects, these differences had major consequences for the practical efforts involved in each project. Experiences of this kind brought this author (Gustavsen, 1976) to argue that initially the world has to be seen as chaotic rather than as subject to systems theoretical principles, and that efforts at change have to consider the need to see the understanding of each situation as a process of active constructivism rather than as one of discovering something given. Elden (1983) introduced the notion of local theory: When a situation is to be understood, a number of possible concepts are generally pulled in. While many of them come from the established portfolio of concepts in organization theory, the choice of which ones to use and how to combine them to form a map of the situation takes on unique, local characteristics.

From the need for understandings based on local conditions, there followed a need for more influence from the workplace actors over the change processes. This 
need came to the surface in the job design seminar and in a number of other efforts as well, and gave rise to notions like participative design and even user-driven change within the QWL movement in general. Although Elden (1979) pointed out that the QWL movement consisted of several generations of projects, the tendency among the core actors of the movement, such as Trist (1981), was to see the changing character of the field efforts as a linear transformation emanating from a common point of departure, so that the notion of one movement representing one single general reason could be maintained. None of the authors that pointed out differences and discontinuities in the QWL movement made any effort to initiate a broad discourse on the general theory behind the movement, nor did the council established to lead the movement take any initiative in this direction. This discourse instead appeared in full force in another context: When Eric Trist went into retirement in 1987, the QWL center in Ontario organized a conference for researchers involved in the movement. About 50 researchers met, expecting an ordinary research event with mutual presentations of cases and other experiences with a view to providing each of the participants with ideas about how to make progress within one's own context. The organizers had, however, invited an external speaker and the choice had fallen on Gareth Morgan who had recently published «Images of organization» (Morgan, 1986), promoting the view that there is no single best way of understanding an organization; this way relies instead on local or other specific circumstances and on why an understanding is sought at all. This made for a head-on collision with Emery and his notion of general theory and universal reason. There is, unfortunately, to the best of this author's knowledge, no published material from this event, such as the presentations of the main contestants, or other contributions pertaining to the core controversy. It is a fact, however, that this was the last event within the QWL movement, as it had appeared in the 1981 conference. Whatever continued in terms not only of projects but also of social networks surrounding these projects turned local, regional, or national. Insofar as international relationships continued or emerged, they reflected different interests than the one of pursuing a universal theory.

A simple interpretation of this development is that "The battle of Orillia», as it was called in an unpublished report by Merrelyn Emery, was won by the postmodern perspective and that Emery's universal theory evaporated there and then. There is, however, another explanation that moves in from the practical angle rather than from the theoretical:

To verify a claim to universal reason through its social impact, there is a need for a fairly substantial impact. The QWL movement had to be not only strong but broad as well. Since it was a core characteristic of this movement to use research as a particpant in the field processes, there was a need for many researchers distributed over many contexts. These researchers all had, however, practical needs, paramount among these was of course the need for financing, something that brought the researchers into relationships to Academia, research councils, and similar in their home environments. If the theory behind the QWL movement had had a strong academic presence on the global level, it could possibly have provided the researchers with an umbrella of strength sufficient to provide academic coverage for the practical needs. This, however, was not the case. In spite of being expressed in a substantial number of publications, of which some also received a wide circulation, there are few traces to be found of discourses of Emery in the international academic community. Even though Emery held 
strong views on many of the issues that appeared as major during his lifetime, such as on critical theory (reflected in an unpublished paper titled «The historical validity of the industrial democracy program» expressing a critique of Marcuse), on Mao (as reflected in another unpublished paper called «Mao's vision of China's future»), on democracy, post-modernism, the linguistic turn, and more, these views were not promoted in the most impact rich academic discourses, insofar as they were promoted in published texts at all. There may be different reasons for this, not least the one that the theory was to be validated more through its social impact than through academic discourse. The practical consequence was, however, that the lack of a broadly recognized academic umbrella for the QWL movement strengthened the need to turn contextual for the researchers involved. To come to terms with their own environment, they needed to relate to whatever discourses prevailed in this environment and develop their ideas accordingly, alternatively to create new schools of thought on work and change.

Should the notions behind the original QWL movement be seen as a historical parenthesis? Since the half century that has passed since the QWL theory was developed, some changes of a general kind have occurred in the way theory is looked upon. There is a growing recognition of the distinction between validity and exclusivity. It is possible to accept a theory as valid for an area without implying that it is the only theory valid for this area. This calls for complex relationships between different theories, but over the years, many combinations of theories have been worked out in different areas, working life not excluded. It is, consequently, possible to argue that Emery's theory contains points of relevance and validity without excluding that a number of other theories may have similar to offer.

Emery's core point is the need to anchor workplace change in democracy. In a sense, democracy comes before all other concerns, such as economic progress, productivity, and innovation. Unless the overall framework is democracy, there will never be peak performance within the other areas. At the time when Emery worked out his theoretical platform, there was no lack of attacks on democracy. In spite of efforts at holding forth phenomena such as producer cooperatives (in particular Mondragon), the kibbutz movement, Yugoslav self-management, and Eastern European work brigades, they did not really prove convincing challenges to the leading position of the democracies as producitivity and innovation are concerned. Today, this is different. The emergence of the Chinese combination of authoritarianism and economic success, the failure of democratic Europe to fence off a sequence of crises, the tendency of whole populations, such as in several of the Eastern European countries, to voluntarily prefer semi-democracies to full democracies, and more, makes the need to investigate the link between democracy and issues like producitivty, innovation and, for that matter, the ecological and climatic challenges, even more urgent than it was during the latter part of the previous century. On this background, there are good reasons to consider how the idea of the necessity of democracy can be carried on. In a sense, one can say that the postmodern perspective that once knocked Emery out has brught him back in business again. In doing this, it is, however, necessary first to «turn local» and only at a later stage start discussing issues like generalizations on the global level. Below, it is experiences from the Nordic countries in the period from the middle 1980s and until today that will be used. 


\section{Democracy and its sources}

While the notion of anchoring work reform in the need to counter turbulence may constitute a fruitful point of departure in some cultures, there were reasons for thinking along different lines in the Nordic context. In their reports from the ID program, Emery and Thorsrud $(1969 ; 1976)$ themselves underlined the major importance of the cooperation between the labor market parties, and the cooperation between these parties on the one hand and the political/public institutions on the other hand, in the possibility of launching the program. Do the labor market parties have anything to do with democracy? Looking in particular at the union movement and the reasons it provides for its own existence, what stands forth are the freedom of association, the freedom of speech, equal treatment of equal cases, the right to pursue one's own interests, the right to be heard before being made subject to decisions, the prohibition of retroactive decisions, and similar. The unions are there to see to it that their members can sustain these rights. These rights are taken directly out of the declaration of human rights, which is a major part of all democratic constitutions. In fact, since the human rights are part of the charter of the United Nations and signed by all member countries, it can be said to be the most universal of all social constructions. In principle, these rights can be summarized as the right to free association and free communication. Be it as reflexes of the union movement, or as products of constructive forces of their own, in the Nordic countries, the employer associations emerge from the same foundation. In seeking a democratic point of departure for workplace development, this emerged not only as reasonable but also as necessary within the Nordic context. This implies to seek historical rather than analytical reasons for democracy. It can be of interest to note that in the abovementioned paper called «The historical validity of the industrial democracy programme», Emery founded the program just in the historical evolution of society.

Working from this point of deparure also helped deal with another issue: As long as an autonomous work role was seen as the basic condition for democracy, people in narrowly defined jobs could not function as democratic actors before their roles had been changed. In principle, projects like those in the ID program would have to be decided over their heads. By emphasizing communicative competence as the chief prerequisite for participation, it was possible to bypass this problem, at least to some extent. There was much evidence demonstrating that even people in narrowly defined jobs could have fruitful opinions about their own work situation. The communicative angle also made it easier to accept the local unions as fully legitimate spokespersons for their members.

The emphasis on freedom and communication has some degree of parallel to the kind of position argued by Habermas (McCarthy, 1996), and seems open to the critique that it is no less an example of universal reason than Emery's QWL theory. Since this happens now and then, it may be worth while to emphasize that it differs in two very important respects: First, it does not seek the basis for free communication in the implicit stipulations made when arguing truth or justice, but in historical sources such as the declaration of human rights, and, second, it emphasizes the practical-operational aspects of free communication as the core ones rather than underlying, but hidden, reasons of a theoretical nature. 


\section{Democracy and its practical expressions}

When, in the period from the middle 1980s and onwards, the possibility emerged of launching a new generation of workplace development initiatives, democratic communication was the point of departure. Linking to such characteristics as those actually defined in the declaration of human rights, the challenge was to move from the point of departure to the point of operationals. Several events were decisive in this context. Here, the workplace agreement made between the labor market parties in Norway in 1982 will be used as an example, since research participated in its formation:

In exercising their democratic rights and duties, the labor market parties traditionally relied on negotiations. Communicative freedom could be seen as expressed by free negotiations. Experiences from the ID program and related projects had, however, demonstrated that complex local processes could hardly be fully handled through negotiations. There was a need for broader forms of communication. In approaching this issue, what was done was to reverse the characteristics of negotiations and imagine a type of conversation occurring between all concerned rather than representatives only, covering all kinds of topics rather than mainly time and money, and unfolding in an atmospphere of cooperation rather than one of conflict.

This notion of broad communciation was further developed during the first years after the agreement went into force. The main vehicle in this context was a conference where workers and managers in an organization could meet and discuss challenges, ideas, and plans of action. Originally called mapping conference, the concept of dialogue conference was successively taken into use. In the light of experiences and in cooperation with research, a set of critieria operationalizing the notion of dialogue and what setting it calls for were worked out. Among these criteria could be found points such as all participants being equal on the dialogue arena, that work experience was to be the point of departure for the discussions, that all participants were under the obligation to not only present their own views but also to help others present their, that all participants were under the force of accepting the best argument, and that the outcome of the dialogue should be a plan for joint practical action. The number of participants could vary, but the ideal was around 40 . To make sufficient space for each participant, most of the discussions were performed in groups, and with 40 participants it fell natural to use four groups. The composition was an inverted $\mathrm{T}$, with all levels of management and a broad participation from the shop floor. Duration varied between one and three full working days. There are not only many points of resemblance between dialogue conferences and search conferences, but also differences. While search conferences are built on a radically realist postion as the perception of the surrounding world is concerned, the dialogue conference has more of a constructivist background and a corresponding emphasis on the development of language needed to reach agreement on practical action (Gustavsen, 1992).

The conferences became quite popular during the 1980s and 1990s. They seemed to meet a need not only from the employees but also from the management. Distant relationships, now and then broken by negotations, were no longer felt to be adequate to the tasks facing the organizations. The existence of the agreement and the possibility of some support in terms of financing and consultancy made it easier to propose dialogue conference as a measure in organization development. The archives of the labor market parties do not make it possible to provide exact figures as the use of dialogue 
conferences is concerned, but for the whole period 1983 to about 2010, the estimate is that the number of enterprises using the agreement was about 2000, of which most applied conferences, many several times. As more deep going changes in the short and middle run are concerned, the estimate is this can be found in about one quarter of the users.

During this period, transformations did, however, occur. While the first phase was characterized by a strict adherence to the criteria worked out initially, the practical expression of dialogue went into a phase of growing pluralism, as the notion of dialogue conference was merged with other procedures, as well as with other arenas such as works councils. The rapid growth in the use of «dialogue» on the level of society and the world in general has also had an impact. It seems reasonable to assume that many conversations are more dialogic today than they were, say, 20 years ago. That this broad popularity has led to a watering out of the concept seems, however, also clear and that this watering out makes itself felt in processes of work reform seems equally clear.

"The dialogic turn» is illustrated by the agreement on workplace development between the labor market parties in Norway. Exactly similar agreements did not emerge in the other Nordic countries but related agreements and other initiatives triggered similar turns. While the labor market parties could not be bypassed, traditional negotiations was too narrow a form of communication to meet the needs.

Nor were the agreements on workplace development the only force behind a dialogic turn. In the major health and safety reforms appearing during the 1970s, there was, in all the Nordic countries, seen as important to cover such challenges as organizational and psychosocial problems, problems of physiology and ergonomics, the effects if interaction between different hazards, and the effects of long-term exposures to hazards below the formal threshold limit values. Common to these is that they cannot be made subject to regulation through specification but are in need of local programs for continuous improvement. This, in turn, calls for local cooperation and for a medium in which this cooperation can take place.

\section{A new generation of workplace development programs}

Under the new agreements, new research-supported development programs emerged. First out was Sweden with the LOM program (1985) followed by Center for a Better Working Life (SBA) in Norway (1988), Enterprise Development 2000 in Norway (1994), and The Workplce Development Programme in Finland (1996). The LOM program is presented in Gustavsen (1992) and in Naschold (1993); SBA in Qvale (1994) and Davies et al (1994), the Finnish program in Alasoini and Kyllönen (1998) and Arnkil et al (2004), and Enterprise Development 2000 in Gustavsen et al (2001). In Denmark, there appeared no program specifically designed to incorporate research, but in the 1990s, there appeared two programs - one to combat monotonous work and one to promote work as a source of learning and development - where ideas promoted by research played a role and where research appeared in supportive functions in a number of contexts (Hvid, 2000).

In addition to relying on democratic forms of communication as the main driver in the process of change, the programs aimed at creating projects all over the respective countries through a distributive pattern. A number of research groups in different 
locations were invited to participate, together with organizations in their own home environment.

Beyond the notion of dialogue or related criteria as sanctioned by the labor market parties or public authorities, and goals such as increased productivity and innovation, there were no universal requirements placed upon the research groups and their partners. They could create whatever understanding of their situation they found appropriate, drawing upon whatever theories they found to be a help in this context. In this way, all the programs became characterized by a high degree of conceptual and theoretical pluralism.

Although perhaps most strongly in the Norwegian program, they all supported relationships not only between researchers and enterprises but between enterprises networks, clusters, and similar - as well, regional relationships included.

What did the programs achieve? In an evaluation of the LOM program (Naschold, 1993), it appeared that about 150 organizations had made an effort to relate to the program, of which about half had started a specific project, out of which about threefourths had achieved significant improvements in labor-management cooperation. Only about five to seven of the participating enterprises had, however, moved on to perform more substantial technological and/or organizational innovation. Within its limits, then, it can be said that the program proved its ability to influence cooperation, but not the superiority of democratic communication in terms of, say, innovation. The evaluation committe (consisting of a professor of worklife policy, a member of the supervisory board of Daimler Benz Holding AG, and a head of section from the German Metalworkers Union) did, however, not ascribe this to weaknesses in the ideas of the program but to its short running time (5 years) and its radical underfinancing (a little in excess of one million Euros per year to support the 70 projects). The need for a longer program period was taken into consideration in Norway as well as in Finland when the first programs were succeeded by new ones along similar lines (in Norway by Value Creation 2010, in Finland by an expanded version of the Workplace Development Programme; overviews of the lines of evolution characterizing this sequence of programs can be found in Gustavsen, 2011, and in Alasoini, 2013). Although the budgets for the programs have varied, all the programs are, when looking at the relationship between budgets and number of participating organizations, low cost. This must, however, be seen not only in he light of budgetary constraints but also in the light of the point that their purpose is to mobilize the workplace actors to improve on processes that would be ongoing anyway and subject to financing from many sources, also as the research contributions are concerned. The programs aim at recruiting as many participating organizations as possible and an increase in expenditure per participating organization would in principle be against the idea of the programs. There are, however, strong reasons for increasing the scope of the programs, to bring in more organizations, more ideas, and in general increase the store of impulses availabale within each development coalition.

There are a number of further evalutions, such as Davies et al (1993), Bakke (2001), Arnkil et al (2004), and Arnold et al (2005). They emerge from different perspectives and draw different conclusions, but they also confirm the ability of research to promote democratic communication in organizations and to do this on a scale that encompasses substantial parts of working life. These improvements pertain, furthermore, not only to labor and management within individual organizations but also to communication

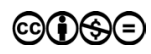


within networks and clusters of organizations, between enterprises and public actors, within regional contexts and more. Since the effects of increased participation on each specific organization are difficult to identify and even more difficult to measure, there is no unequivocal picture to be made of their total impact on Nordic working life. The programs involving research can, furthermore, not be fully separated from other but related programs and efforts. In addition to the Danish programs mentioned above, The Work Life Fund in Sweden can be brought to mind, generating, with a budget of more than one billion Euros, 25,000 projects over a 5-year period (1990-1995), reaching about one half of the total Swedish labor market. While the ID program was intended to constitute a spearhead of four projects to be followed by measures to achieve broad diffusion, the more recent programs are based on creating a large number of projects and then accepting that not all lead to identifiable changes. The programs do not promote communicative change only. There are many other themes on the agendas as well, including the kind of sociotechnical redesign that was the core content of the first field experiments. None of these other themes are, however, present in all projects and even when they are, they appear in new versions.

The programs help prove the link between democratic forms of communication and the ability of the actors concerned to develop forms of work organization providing freedom, competence, and decision-making rights for all concerned. The positive links between these forms of work organizaton and productivity are verified in a large number of studies of many different kinds. The positive links to innovation are as yet more tentative. The major critique against the programs has not been lack of efficiency as the ability to promote cooperation is concerned, but insufficient capacity to help the participating orgnizations utilize the improvements to make more substantial breakthroughs in terms of sociotechnical improvements and innovations. To adequately respond to this critique, it is necessary to expand the budgets, increase the time frame or link the programs more strongly to other initiatives, such as technology programs. With some exceptions, mainly for Finland, these responses are lacking in the Nordic countries. For this, it is easy to blame research councils and other research policy authorities. The issue is, however, more complex and, as we will turn to below, some of the responsibilty rests with research itself.

\section{Challenges}

From the evaluation of Enterprise Development 2000, it appeared that an important reason for local parties to seek research support was the neutrality of research (Bakke, 2001). With its commitment to values such as truth and its organization largely in terms of publicly owned but professionally independent establishments, research has a platform for functioning in the borderland between different interest groups, such as workers and managers. With the continuous decline in the level of experienced conflicts in working life, the tendency to seek research support is on the decline as well. Research needs to make it more explicit what kind of third-party contributions it is to make. In the Nordic countries, this discussion occurs, to an increasing degree, within the framework of the notion of innovation system (Asheim, 2011), but can also be approached within the framework of other concepts, such as development coalition, social movement, and more. 
When the change projects emerge from the day-to-day operations of the user organizations, they flow, to an increasing degree, into their own backgrounds and become correspondingly difficult to identify. In spite of the impossibility of doing this in full, it needs to be done better than what is generally the case today. Research can hardly expect unidentifiable developments to be made subject to generous public financing.

This leads to the third, and most critical, of the contemporary challenges: The need to strengthen the links between different projects. While much social theory has tended to start with broad generalizations and then «move downwards», the local turn described in this paper has, by now, gone too far in the other direction. Cases are presented one by one and even authors who have generated a number of cases over time tend to report each case separately, often without reference to the other cases and even less to the cases of other researchers within the same movement. Along with this, there is also still a strong tendency toward overtheorizing, making each case resembling a small group of figures with a huge speak-bubble over their heads. Since the notion of social movement refers just to a number of parallel processes where none are outstanding, the point that the contributions of research are generally associated with low-visibility single cases rather than with the movement as a whole does not only make the contributions difficult to identify, they appear as fragmented as well.

But how to become more general without falling victim to the problematic aspects of general theory and universal reason? The answer is to generalize as far as the material allows for, and when the material emerges from participation in processes of organizational change, the generalizations have to start with comparing cases. Even when each case is, as a point of depature, subject to local theory, there will be concepts that appear and measures that function in more than one case. Comparisons will make different complexes of understandings and measures appear where each complex will contain more than one case. From this meso-platform, it may be possible to continue «upwards» toward the continuously more general. Irrespective of what comes out of it, this kind of «bottom-up» comparison will help make the notion of the cases belonging to a shared movement more visible.

\section{Conclusion}

Of the heritance left by Emery, the core significance of autonomy in work, its anchoring in democracy, and the need to see workplace development as an issue on the level of society have not only survived but also been strengthened in the intervening years. What has not been strengthened is the idea of steering a global reform movement top down through one single theory claiming to represent universal reason. For a movement to achieve scope and become broad, it has to confront numerous realities that have something in common but that also show differences, not least as those aspects that concern operationals are concerned. To be able to respond to these differences, change has to be built bottom-up. While notions such as user-driven design and local theory can be interpreted to mean that all change is local, the concept of bottom-up indicates that there is not only a bottom but also a way upwards. This way has to start with the linking and comparing of local experiences. Out of even a substantial number of cases, there will emerge little of interest as long as each case does not only stand alone but is baked into layers of abstract theory as well.

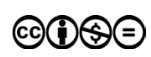




\section{References}

Alasoini, T. (2013). Two decades of programme-based workplace development in Finland: Past experiences and future challenges. The International Helix Conference, June 12-14, Linkøping, Sweden.

Alasoini, T and Kyllönen. M (eds.) (1998). The crest of the wave. Helsinki: Ministry of Labour, National Workplace Development Programme (overview TYKES, first phase).

Arnkil, $\mathrm{R}$ et al (2004). The Finnish workplace development programme: A small giant? Concepts and Transformation, Volume 9, Issue 3, 2004, pages: 249-278 DOI: http:// dx.doi.org/10.1075/cat.9.3.03arn.

Arnold E, Allesandro M, Nählinder, J and Reid A (2005). A mid-term evaluation of Value Creation 2010. Brighton: Technopolis.

Asheim, BT (2011). Learning, innovation and participation: Nordic experiences in a global context with a focus on work organization and innovation systems. In Ekman, M, Gustavsen, B, Asheim, BT and Pålshaugen, Ø (eds.) Learning regional innovation. London: Palgrave-MacMillan: 15-49. doi: http://dx.doi.org/10.1057/9780230304154 2.

Bakke, NA (2001). The report to the benchmarking group. In Gustavsen, B, Finne, H and Oscarsson, B. (eds.) Creating connectedness. The role of social research in innovation policy. Amsterdam: John Benjamains: 41-47.

Davies, A, Naschold, F, Pritchard, W and Reve, T (1993). Evaluation report commissioned by the board of the SBA programme. Oslo: Work Research Institute.

Ejnatten, FM (1993). The paradigm that changed the workplace. Assen: van Gorcum.

Elden, JM (1979). Three generations of work democracy experiments in Norway: Beyond classical socio-technical systems analysis. In Cooper, CL and Mumford, E (eds.) The quality of working life in Western and Eastern Europe. London: Associated Business Press: 226-257.

Elden, JM (1983). Democratization and participative research in developing local theory. Journal of Occupational Behaviour. 4(1): 21-34.

Emery, FE (1959). Characteristics of socio-technical systems. London: Doc. 527, Tavistock Institute.

Emery, FE (ed.) (1969). Systems thinking. Harmondsworth: Penguin.

Emery, FE and Thorsrud, E (1969). Form and content in industrial democracy. Assen: van Gorcum.

Emery, FE and Thorsrud, E (1976). Democracy at work. Leiden: Nijhoff.

Emery, FE and Trist, EL (1965). The causal texture of organizational environments. Human Relations, 18(1): 21-32. doi: https://doi.org/10.1177/001872676501800103.

Emery, FE and Trist EL (1972). Towards a social ecology. New York: Plenum Press.

Emery, M and Emery FE (1978). Searching for new directions in new ways for new times. In Sutherland, JW and Legasto, A (eds) Management handbook for public administrators. NewYork: Van Nostrand Reinhold.

Engelstad PH and Ødegaard, LA (1977). Participative design processes in Norway: Summarizing the first five years of a strategy to democratize the design processes in working life. Quality of Working Life Council (ed.) Working on the quality of working life. Leiden: Nijhoff: 327-338.

Gustavsen, B (1977). Aktionsforskning. Stockholm: Rapporter 13, Psykologiska Institutionen, Stockholms Universitet [Action Research].

Gustavsen. B (1992). Dialogue and development. Assen: van Gorcum.

Gustavsen B, Finne H and Oscarsson B (2001). Creating connectedness: The role of research in innovation policy. Amsterdam: John Benjamins.

Hvid, H (2000). Dansk arbejdspolitiks gyldne tiår. Tidsskrift for Arbejdsliv 3(4): 83-101 [The golden ten years of Danish labor market politics]. 
McCarthy, T. (1996). Pragmatizing communictive reason. In Toulmin S and Gustavsen B (eds.). Beyond theory. Amsterdam: John Benjamins: 159-178. doi: http://dx.doi.org/ 10.1075/dowi.2.12mcc.

Morgan, G. (1986). Images of organization. Beverly Hills: Sage.

Naschold, F (1993). Organization development: National programmes in the context of international competition. In Naschold, F, Cole, R, Gustavsen, B and Beinum H van Constructing the new industrial society. Assen: van Gorum: 3-105.

Quality of Working Life Council (ed.) (1977). Working on the quality of working life. Leiden: Nijhoff.

Qvale, TU (1994). The case of the SBA: A five year program on participation, productivity and institutional change. In Kauppinen, $\mathrm{T}$ and Lehtonen, $\mathrm{M}$ (eds.) National action research programmes in the 1990s. Helsinki: Labour Policy Studies 86, Ministry of Labour: 157-176 (start 1988).

Selznick P (1957). Leadership in administration: A sociological interpretation. NewYork: Harper and Row.

Trist, EL and Bamforth KW (1951). Some social and psychological consequences of the longwall method of coalgetting. Human Relations 4(1): 3-38. doi: http://dx.doi.org/ $10.1177 / 001872675100400101$. 